\title{
Magnitude and predictors of undernutrition among children aged six to fifty nine months in Ethiopia: a cross sectional study
}

\author{
Hiwot Darsene ${ }^{1 *}$, Ayele Geleto ${ }^{2}$, Abebaw Gebeyehu $^{3}$ and Solomon Meseret ${ }^{3}$
}

\begin{abstract}
Background: Undernutrition among children continues to be a major public health problem in developing countries. In Ethiopian, 44\% of under-five children were stunted while $29 \%$ and $10 \%$ were underweight and wasted respectively. However, predictors of undernutrition among children were not clearly known in the study area. Therefore, this study was aimed at determining prevalence and predictors of undernutrition among children aged 6-59 months in Hawassa town.

Method: A community based cross-sectional study was conducted among 811 randomly selected children paired with their mothers/caregivers. Mothers/caregivers were interviewed to obtain social-demographic data and feeding practice. Anthropometric measurement was conducted to obtain anthropometric data. Data were entered into EPI info 6.04 and exported to SPSS 16 for analysis. Bivariate logistic regression analysis with Crude Odds Ratio at 95\%Cl was used to assess presence of association among variables. Multivariate logistic regression analysis with Adjusted Odds Ratio at $95 \% \mathrm{Cl}$ was conducted to determine predictors of undernutrition and association was declared significant at $p \leq 0.05$.
\end{abstract}

Result: The result of our study indicated that $39.3 \%, 15.8 \%$ and $6.3 \%$ of children were stunted, underweighted and wasted respectively. Multivariate logistic regression analysis identified male sex, mother older than 35 years, not fed on colostrum, cessation of breastfeeding before two years of age, frequency of complementary feeding per day and diarrheal morbidity in the last 12 months were statistically associated with stunting. Maternal education, family sizes and diarrheal morbidity in the past 12 months were significantly associated with underweight. Similarly, frequency of complementary feeding per day, age at cessation of breastfeeding, preceding birth interval and not fed on colostrum were associated to wasting.

Conclusion: The prevalence of undernutrition; stunting, underweight and wasting, among under-five children is very common in the study area. Inappropriate feeding practice and diarrheal morbidity were found to be the main risk factors for undernutrition. Appropriate factor specific interventions including counseling on optimal child feeding practice and diarrhea prevention should be strengthened in the study area.

Keywords: Children, Stunting, Wasting, Underweight and undernutrition

\footnotetext{
* Correspondence: amu.2014.ayu@gmail.com

${ }^{1} \mathrm{MCHN}$ Directorate, Federal Ministry of Health, Addis Ababa, Ethiopia

Full list of author information is available at the end of the article
} 


\section{Operational definition}

Kebele: the smallest administrative structure with household number of nearly 500 .

Sidaminga: the widely spoken language (local language) of the study area.

Chembelala: A well known traditional festival that is celebrated in the study area and considered as a new year. Diarrheal morbidity: Passage of three or more loose or liquid stools per day (or more frequent passage than is normal for the individual).

\section{Background}

Adequate nutrition is essential during childhood to ensure healthy growth, proper organ development and function, a strong immune system, and neurological and cognitive development. Children undernutrition continues to be a major public health problem in developing countries. Global data indicated that 60 million children are moderately malnourished while approximately 13 million children faced severe acute malnutrition. Globally, undernutrition contributes for more than one third of child deaths which can be prevented through public health interventions [1-3].

Undernutrition can affect children's health and learning ability during their adulthood life. Children with undernutrition are usually suffered from chronic illnesses [4]. Survivors of malnutrition can suffer from impaired physical development and intellectual abilities, which in turn may diminish their working capacity with negative effects on economic growth. Child malnutrition may also lead to higher levels of chronic illness in adult life and these may have intergenerational effects, as malnourished females are more likely to give birth to low-weight babies [5].

Globally it is estimated that $35 \%$ of deaths among under-five children is attributed to under nutrition. Over two-thirds of these deaths, which are often associated with inappropriate feeding practices, occur during the first year of life. In developing countries nearly one-third of children are underweight or stunted. Under nutrition is a risk factor for infectious disease and deaths [6].

Ethiopia is a country with remarkable progress in reducing under-five mortality [5]. On the other hand, currently undernutrition among children is a common health problem in the country [7]. In Ethiopia, undernutrition is a major public health problem that occurs throughout full year round because of long term household food insecurity. Undernutrition is the underlying cause for $57 \%$ of child deaths in the country. Different studies conducted in Ethiopia, including the national data, indicated high prevalence of undernutrition among children. The Data from Ethiopian Demographic and Health Survey (EDHS) 2011 indicated that 44\% of under-five children were stunted while $29 \%$ and $10 \%$ were underweight and wasted respectively [5].

Study done in Vietnam revealed that the prevalence of underweight, stunting and wasting was found to be $31.8 \%, 44.3 \%$ and $11.9 \%$, respectively [8]. Similarly, $48 \%$ of under-five children in East Africa are stunted [9]. Many nutritional studies have demonstrated that in Ethiopia undernutrition is a serious problem with regional variations of $51.4 \%$ in Tigray, $41.4 \%$ in Oromia and 44.1 in Southern Nation, Nationality and People Region (SNNPR) [5].

Undernutrition in developing countries in general and in Ethiopia in particular is highly prevalent. Knowledge on the level of undernutrition and its contributing factors is therefore an important prerequisite for developing strategies of nutritional intervention. However, there is no recent study which identified prevalence and predictors of undernutrition in the study area. Therefore this study was designed to identify prevalence of undernutrition and associated factors among children aged 6-59 months in Hawassa town.

\section{Methods}

\section{Study design and setting}

A community based cross-sectional study was conducted among children aged six to fifty nine months paired with their mothers/caregivers in Hawassa town. Hawassa town is located at $275 \mathrm{~km}$ south of Addis Ababa, the capital of Ethiopia. It is the regional capital of SNNPRs with multi diverse ethnicity, language, culture and life style. The city administration has eight sub-cities and thirty two kebeles. Tulla sub-city is among the eight sub-cities found in Hawassa Town. Tulla sub-city has 12 kebeles. According to the 2007 national census it has a total population of 100,790 of which under- five children and children in the age group of 6-59 months constitute 15,723 and 15,219 respectively. This study was conducted from August to September 2012.

\section{Study participants}

The study population of this study was the 811 randomly selected six to fifty nine months old children paired with their mothers/caregivers who lived at least for six months in Tulla sub-city, Hawassa town with exclusion of children with disabilities that poses difficulty during anthropometric measurements.

\section{Sample size and sampling technique}

The sample size was calculated using a single population proportion formula $\left[n=(Z \alpha / 2)^{2} \mathrm{p}(1-\mathrm{p}) / \mathrm{d} 2\right]$ [2]. In Ethiopia, $44.1 \%$ of under-five children are stunted (P) [5];95\% confidence interval and 5\% marginal of error (d) were used to calculate sample size. Since a multistage sampling technique was employed to identify study 
participants, a design effect of 2 was used [2] and 10\% non-response (refusal and closed houses after three repeated visit) was considered. Accordingly, the final sample size was calculated to be $n=\left[(1.96)^{2}\right.$ $(0.441 \times 0.559] /(0.05)^{2}=834$.

A multistage sampling technique was used to identify study participants. First of all, Tullu sub-city was selected by simple random sampling (lottery) method from all sub-cities of Hawassa town. Then five Kebeles of Tulla sub-city (Tullo, Finchawa, Gemeto, Chefecotigebesa and Garareketa) were selected from the twelve kebeles of the sub-city again by lottery method. An estimated 5,842 households with eligible children were found in the selected kebeles. The sample size was proportionally allocated to the selected kebeles based on the total number of eligible households found in each kebele. Systematic sampling method was used to identify participants' households from each kebele. When there were two or more eligible children in the selected household, one child was selected by lottery method to be included in to the study (Fig. 1).

\section{Data collection}

Quantitative data were collected using structured questionnaire. Interviewer administered was used to collect socio-demographic data of mother/caregiver, child characteristics and child caring/feeding practices. The questionnaire was prepared in English language after different literature review and translated into Sidamigna language for data collection. Three female clinical nurses and three Health Extension Workers (HEWs) were recruited to collect data and three public health professionals in nutrition were recruited to supervise the data collection process in addition to investigators. For ensuring data quality two days training was provided for data collectors and supervisors. Anthropometric data were collected through measurement of length/height and weight of all children.

Weight and length/height of the children were obtained by anthropometric measurements. For children less than two years weight was measured using hanging weight scale and length was measured in recumbent position using wooden UNICEF height board. Weight for children older than two years was measured using

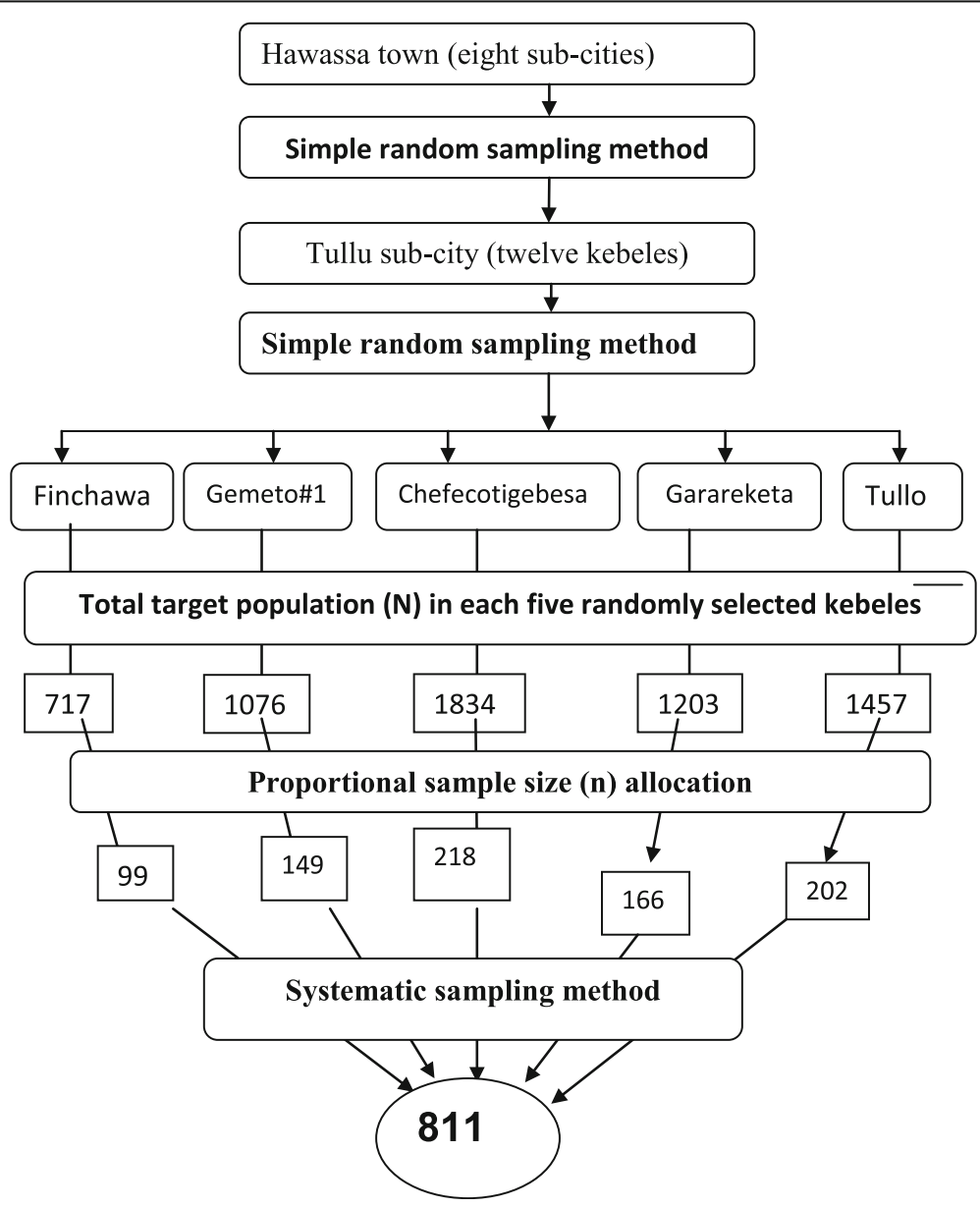

Fig. 1 Schematic presentation of sampling technique, Hawassa town, Southern Ethiopia, 2012 
seca digital weight scale to the nearest $0.1 \mathrm{~kg}$ and height was measured in standing position to the nearest $1 \mathrm{~cm}$ using UNICEF wooden height board. Calibration for the weight and height instruments was done upon every case examination. All measurements were taken twice and the mean value was used for data analysis. The child's age was collected from vaccination cards. In case, there were no vaccination cards or any age records, a local calendar system (including Chembelala, Genna (charismas), Fasika (Easter), Meskel (the finding of true cross), Enkutatesh (Ethiopian new year), Remadan, Arefa and other locally known festivals) were used to estimate the child's age.

\section{Study variables}

Dependent Variable: The dependent variable in this study was undernutrition indicated by wasting, stunting and underweight status in children 6-59 months of age.

Independent variables: Four categories of factors were assessed as independent variables:

- Socio-demographic variables: Age of child and mothers, child sex, family size, household monthly income, maternal education and occupation and marital status of the mother

- Child characteristics: height, weight, birth order and childhood illness.

- Child feeding practices: exclusive breast feeding, colostrums feeding, duration of breast feeding, frequency of complementary feeding, bottle feeding and child immunization

- Maternal characteristics: number of children ever born and ANC visits [10].

\section{Data analysis}

The data were exported to SPSS version 16 after it was coded and entered in the computer using Epi Info Version 6.04 statistical packages. Descriptive statistics was used to summarize the data and the results were presented using frequency tables and percentages. For the anthropometric measurements data analysis was performed using Emergency Nutrition Assessment (ENA) for SMART 2007 software. ENA for SMART 2007 software was used to convert the anthropometric measures; weight, height/ length and age values into $\mathrm{Z}$-scores of the indices; Heightfor-Age(HAZ), Weight-for-Height(WHZ) and Weightfor- Age(WAZ) taking sex into consideration. The WHO classification was used to classify the nutritional status of the children. A low height-for-age, below -2SD of the reference population indicates stunting while below -3SD indicates severe stunting. A low weight-for-height, below -2SD of the reference population, indicates wasting, while below-3SD indicates severe wasting. A child with a weight-forage below -2SD of the reference population is underweight while a child below -3SD is severely underweight [11].

Both bivariate and multivariable logistic regression analysis were employed to determine predictors of undernutrition. All variables found to be associated to undernutrition in bivariate analysis using Crude Odds Ratio with $95 \% \mathrm{CI}$ at significant level of $\leq 0.2$ were taken to multivariable regression analysis in order to control confounders. Adjusted Odds Ratio with 95\%CI was used to determine degree of association between explanatory variables and nutritional status of the respondents. Statistical association between dependent and independent variables was declared significant at $p$-value of $\leq 0.05$.

\section{Data quality management}

The questionnaire was pre-tested on $5 \%$ of sample size in non selected kebeles to check the applicability of the questionnaire and feedback was used to make some modifications to the questionnaire [2]. Members of field staff were selected according to their qualifications and work experience in the field of data collection. Field staffs were given training before starting data collection. During training the objective of the study and method of data collection were discussed. Furthermore, each question included in the questionnaire was discussed in detail. The collected data were checked for its completeness and consistence each day by supervisors and investigators. Incomplete questionnaires were completed by making second visits to the homes. Data were also cleaned and rechecked after double data entry was performed. Weighing scales were calibrated and the scales indicator was checked against zero reading after weighing every child.

\section{Ethical consideration}

Ethical clearance was obtained from Ethical Review Board of the Institute of Public Health, University of Gondar. Official letter of cooperation was written to Hawassa city administration health office by SNNPRs regional health bureau ethical review committee. Subsequently, permission from Tulla Sub city health office was obtained and each administration of the kebele was informed through letter from the sub city. Written and signed informed consent was obtained from each respondent after the purpose of the study and assurance of confidentiality was explained. It was explained to the participants that participation was voluntary. Participants with diarrhea, respiratory tract infections and undernutrition were referred to nearby health facilities for management. 


\section{Results}

Socio-demographic characteristics of children and parents From the total 834 proposed study respondents, complete response was obtained from 811 respondents making the response rate $97.2 \%$. The mean age of participant children was 30.77 (SD \pm 14.09 ) months for both sexes. Four hundred thirty two (53.2\%) participant children were male. Five hundred eighty six (72.3\%) of the children were born to mothers between 20 and 34 years. Fifty $(6.2 \%)$ and $175(21.6 \%)$ of the children were born from teenage mothers and mothers over 35 years of age respectively. Majority, 781 (96.3\%) of the children were grown by both parents and the average household family size was $5.73(\mathrm{SD} \pm 2)$. Nearly all of the study participants were Sidama by ethnicity $794(97.9 \%)$. In total, $554(68.3 \%)$ of the mothers were housewife and only 444 (54.8\%) were educated. Regarding religion, $720(88.8 \%)$ of the children are belong to Christian families (Table 1).

\section{Healthcare utilization and child feeding practice}

Five hundred ninety eight (73.7\%) of the participated children were exclusively breastfed for the first six months whereas 213 (26.3\%) given mixed feeding. Slightly more than half, $458(56.5 \%)$ of the children had ceased breastfeeding before two years of age. Cow's milk, avocado juice and porridge were commonly used to start complementary feeding. Seven hundred thirty two $(90.3 \%)$ of the children were fully immunized while $61(7.5 \%)$ and $18(2.2 \%)$ children were partially immunized and not immunized at all respectively. Diarrheal disease is highly prevalent among the participant children as $715(88.2 \%)$ of them were reported to be experienced diarrhea within past 12 months. Among the total participated mothers, 292 (36\%) were attended four ANC visit while 63 (7.8\%) of mothers attended no ANC visit during most recent pregnancy. Six hundred sixty six $(82.1 \%)$ of non primigravida mothers gave the next births after 24 months from the previous birth. Nearly two third of the households 528 (65.1\%) in the study area had only one under-five child while the rest $277(34.9 \%)$ had two or more under five children (Table 2).

\section{Prevalence of undernutrition among children}

Depending on the three anthropometric indices, heightfor-age, weight-for- age and weight-for-height, the findings of this study revealed that $319(39.3 \%), 128(15.7 \%)$ and $51(6.2 \%)$ of the participant children were stunted, underweight and wasted respectively. In this study prevalence of severe stunting, severe underweight and severe wasting among the children were 98(12.1\%), $34(4.2 \%)$ and $19(2.3 \%)$ respectively. In general, the prevalence of stunting (chronic undernutrition) increases as
Table 1 Socio-demographic characteristics of the sampled children and their mothers $(n=811)$, rural kebeles of Hawassa town, Southern Ethiopia, 2012

\begin{tabular}{|c|c|}
\hline Variables & Frequency (\%) \\
\hline \multicolumn{2}{|l|}{ Sex of child } \\
\hline Male & $432(53.3)$ \\
\hline Female & $379(46.7)$ \\
\hline \multicolumn{2}{|l|}{ Age of child } \\
\hline $6-11$ & $58(7.2)$ \\
\hline $12-23$ & $195(24)$ \\
\hline 24-35 & 159(19.6) \\
\hline $36-47$ & $214(26.4)$ \\
\hline $48-59$ & 185(22.8) \\
\hline \multicolumn{2}{|l|}{ Age of mother } \\
\hline Less than 20 years & $50(6.2)$ \\
\hline 20-34 years & $586(72.3)$ \\
\hline More than or equal to $35 \mathrm{yrs}$ & 175(21.6) \\
\hline \multicolumn{2}{|l|}{ Family size } \\
\hline Less than 4 people & 271(33.4) \\
\hline 4-6 people & $170(21)$ \\
\hline More than 6 people & $370(45.6)$ \\
\hline \multicolumn{2}{|l|}{ Current marital status } \\
\hline Single & $30(3.7)$ \\
\hline Married & $781(96.3)$ \\
\hline \multicolumn{2}{|l|}{ Religion } \\
\hline Orthodox & $2(0.2)$ \\
\hline Protestant & $694(85.4)$ \\
\hline Catholic & $24(3)$ \\
\hline Muslim & $91(11.2)$ \\
\hline \multicolumn{2}{|l|}{ Ethnicity } \\
\hline Sidama & 794(97.9) \\
\hline Others $^{\mathrm{a}}$ & $17(2.1)$ \\
\hline \multicolumn{2}{|l|}{ Education of mother } \\
\hline No formal education & $367(45.2)$ \\
\hline Primary education & 397(48.9) \\
\hline Secondary \& above & $47(5.9)$ \\
\hline \multicolumn{2}{|l|}{ Occupation of mother } \\
\hline Farmer & $141(17.4)$ \\
\hline Housewife & $554(68.3)$ \\
\hline Merchant & $71(8.8)$ \\
\hline Other $^{\mathrm{b}}$ & $45(5.4)$ \\
\hline
\end{tabular}

${ }^{a}$ Other- Oromo, Amhara, Gurage, Welaita and Hadiya

bother- student, daily laborer, employee (Governmental and private)

the age of a child increases, peaking at 36-47 months of age $(11.1 \%)$. Female participants were more stunted than males. Underweight is also highest at the age group of 36-47 months (4.6\%) and nearly equal male $65(8.4 \%)$ and female $62(7.4 \%)$ were underweight. Slightly more males $29(3.5 \%)$ were wasted than females $22(2.7 \%)$ (Table 3). 
Table 2 Maternal and child healthcare utilization and child feeding practices $(n=811)$, Rural Kebeles of Hawassa, 2012

\begin{tabular}{|c|c|}
\hline Variables & Frequency (\%) \\
\hline \multicolumn{2}{|c|}{ Breast feeding type (first six months) } \\
\hline Exclusive & $598(73.7)$ \\
\hline Mixed & 213(26.3) \\
\hline \multicolumn{2}{|l|}{ Cessation of breast feeding } \\
\hline Before two years & $458(56.5)$ \\
\hline Two years and beyond & 353(43.5) \\
\hline \multicolumn{2}{|l|}{ Feed on colostrum } \\
\hline Yes & $516(63.6)$ \\
\hline No & 295(36.4) \\
\hline \multicolumn{2}{|c|}{ Frequency of daily complementary feeding } \\
\hline At least 3 times per day & $362(44.7)$ \\
\hline Less than 3 times per day & 449(55.3) \\
\hline \multicolumn{2}{|l|}{ Immunization status } \\
\hline Not immunized & $18(2.2)$ \\
\hline Partially immunized & $61(7.5)$ \\
\hline Fully immunized & $732(90.3)$ \\
\hline \multicolumn{2}{|l|}{ ANC visit } \\
\hline At least one visit & $748(92.2)$ \\
\hline No visit at all & $63(7.8)$ \\
\hline \multicolumn{2}{|l|}{ Preceding birth interval } \\
\hline Less than 24 months & 145(17.9) \\
\hline 24 months and above & $666(82.1)$ \\
\hline \multicolumn{2}{|l|}{ Birth order of the last child } \\
\hline First & $128(15.8)$ \\
\hline Second & 143(17.6) \\
\hline Third and more & $540(66.6)$ \\
\hline \multicolumn{2}{|c|}{ Number of under five children in $\mathrm{HH}$} \\
\hline One & $528(65.1)$ \\
\hline More than one & 283(34.9) \\
\hline \multicolumn{2}{|c|}{ Diarrheal morbidity in the past 12 months } \\
\hline Yes & $715(88.2)$ \\
\hline No & $96(11.8)$ \\
\hline
\end{tabular}

\section{Predictors of undernutrition}

Bivariate and multivariate logistic regression analysis was conducted to determine factors predicting undernutrition. Predictors of the three types of undernutrition, stunting, underweight and wasting were analyzed separately. The result indicated that female children $[\mathrm{AOR}=0.40 ; 95 \% \mathrm{CI}(0.21,0.86)]$, feeding breast for at least two years $[\mathrm{AOR}=0.48 ; 95 \% \mathrm{CI}(0.12,0.88)]$ and those who have not experienced diarrheal morbidity in the past 12 months $[\mathrm{AOR}=0.42 ; 95 \% \mathrm{CI}(0.15,0.94)$ ] were less likely to be stunted as compared with their counterparts. However, children who fed complementary feeding for fewer than three times per day were 3 times $[\mathrm{AOR}=3.01 ; 95 \% \mathrm{CI}(1.48,5.58)]$ more likely to be stunted than those who fed at least three times per day. Participant children who didn't receive colostrum were 1.26 times $[\mathrm{AOR}=1.26$; 95\% CI $(1.09,2.87)]$ more likely to be stunted than children who received colostrum (Table 4).

Regarding underweight household family size being more than four were 4.16 times $(\mathrm{AOR}=4.16 ; 95 \% \mathrm{CI}$ $(2.47,9.68)$ more likely to be underweight than children from family size of less than four. Frequency of complementary feeding is significantly associated with undernutrition as children who fed less than three times per day were 2.87 times $[\mathrm{AOR}=2.87 ; 95 \% \mathrm{CI}$ $(1.62,5.38)]$ more likely to be underweight than those who fed at least three per day. Children who didn't face diarrhea in the past 12 monthsprior to the data collection were less likely to develop underweight than children with diarrheal disease [AOR 0.28; $95 \%$ CI $(0.15,0.74)]$. Risk of underweight among children whose mothers have no formal education was 0.32 times less likely than children whose mothers have formal education [AOR 0.68 ; 95\%CI $(0.30,0.93)$ ] (Table 5).

Regarding wasting, it was observed that the likelihood of being wasted was significantly higher for children who were born within 24 months of the preceding sibling. As compared with children who were born within 24 months from the preceding sibling, the risk of wasting was 1.21 times [AOR $=1.2195 \% \mathrm{CI}$ $(1.11,2.34)]$ more likely for children who were born after 24 months. Number of under five years children in the household was also found to be statistically associated with underweight evidenced with that children who were from households with more than one under five children were 1.48 times $[\mathrm{AOR}=1.4 ; 95 \%$ CI $(1.16,4.82)]$ more likely to be wasted compared to children from households with one under five children. Children who didn't practice bottle feeding were less likely $[\mathrm{AOR}=0.52 ; 95 \% \mathrm{CI}(0.14,0.86)$ ] to be wasted compared with those who practiced bottle feeding (Table 6).

\section{Discussion}

This study revealed high prevalence of child undernutrition in the study area. The finding showed that $39.3 \%$ of the children were stunted. Prevalence of underweight and wasting was found to be $15.7 \%$ and $6.2 \%$ ) respectively. The finding of our study showed that child sex, diarrheal morbidity, mothers' educational status, family size, frequency of daily complementary feeding, age at initiation of complementary feeding, colostrum feeding; preceding birth interval and bottle feeding practice were found to be significant predictors of undernutrition.

The finding of our study indicated lower prevalence of undernutrition (stunting, underweight and wasting) in comparison with the 2011 EDHS report in which 44\%, 
Table 3 Prevalence of severe and moderate malnutrition among six to fifty nine months of age $(n=811)$, rural kebeles of Hawassa town, 2012

\begin{tabular}{|c|c|c|c|c|c|c|c|c|}
\hline \multirow[t]{3}{*}{ Nutritional Indices } & \multicolumn{7}{|c|}{ Frequency (\%) } & \multirow[t]{3}{*}{ Total (\%) } \\
\hline & \multicolumn{2}{|l|}{ Sex } & \multicolumn{5}{|c|}{ Age in months } & \\
\hline & Male & Female & $6-11$ & $12-23$ & $24-35$ & $36-47$ & $48-59$ & \\
\hline $\begin{array}{l}\text { Normal HAZ } \\
\text { (HAZ } \geq-2 S D)\end{array}$ & 198(24.4) & $294(36.2)$ & $38(4.7)$ & $123(15.2)$ & $98(12.1)$ & $124(15.4)$ & 109(13.4) & $492(60.6)$ \\
\hline $\begin{array}{l}\text { Moderate stunting } \\
(-3 S D \leq H A Z<-2 S D)\end{array}$ & $119(14.6)$ & $102(12.7)$ & $17(2.1)$ & $56(6.9)$ & $36(4.4)$ & $63(7.7)$ & $50(6.2)$ & $221(27.3)$ \\
\hline $\begin{array}{l}\text { Severe stunting } \\
\text { (HAZ }<-3 S D)\end{array}$ & $62(7.6)$ & $36(4.5)$ & $3(0.4)$ & $16(1.9)$ & $25(3.1)$ & $27(3.4)$ & $26(3.3)$ & $98(12.1)$ \\
\hline $\begin{array}{l}\text { Normal WAZ } \\
\text { (WAZ } \geq-2 S D)\end{array}$ & $339(41.8)$ & $344(42.4)$ & $43(5.3)$ & $174(21.5)$ & $134(16.5)$ & $177(21.8)$ & 155(19.1) & 683(84.2) \\
\hline $\begin{array}{l}\text { Moderate underweight } \\
(-3 S D \leq W A Z<-2 S D)\end{array}$ & $49(6.1)$ & $45(5.5)$ & $12(1.5)$ & 16(1.9) & $18(2.2)$ & $26(3.2)$ & $22(2.8)$ & $94(11.6)$ \\
\hline $\begin{array}{l}\text { Severe underweight } \\
\text { (WAZ <-3SD) }\end{array}$ & $19(2.3)$ & $15(1.9)$ & $3(0.4)$ & $5(0.6)$ & $7(0.9)$ & $11(1.4)$ & $8(0.9)$ & $34(4.2)$ \\
\hline $\begin{array}{l}\text { Normal WHZ } \\
\text { (WHZ } \geq-2 S D \text { ) }\end{array}$ & $370(45.6)$ & $391(48.2)$ & $54(6.7)$ & 185(22.8) & 145(17.9) & 197(24.3) & $179(22.1)$ & $761(93.8)$ \\
\hline $\begin{array}{l}\text { Moderate Wasting } \\
(-3 S D \leq W H Z<-2 S D)\end{array}$ & $18(2.2)$ & $14(1.7)$ & $4(0.5)$ & $6(0.7)$ & $9(1.1)$ & $10(1.2)$ & $3(0.4)$ & $32(3.9)$ \\
\hline $\begin{array}{l}\text { Severe wasting } \\
(\mathrm{WHZ}<-3 \mathrm{SD})\end{array}$ & $11(1.3)$ & $8(1.0)$ & $0(0.0)$ & $4(0.5)$ & $5(0.5)$ & $7(0.9)$ & $3(0.4)$ & $19(2.3)$ \\
\hline
\end{tabular}

Table 4 Factors associated with stunting among children aged between six to fifty nine months of age $(n=811)$, rural kebeles of Hawassa town, 2012

\begin{tabular}{|c|c|c|c|c|c|}
\hline \multirow[t]{2}{*}{ Explanatory Variables } & \multicolumn{2}{|c|}{ Stunting } & \multirow[t]{2}{*}{ COR 95\% Cl } & \multirow[t]{2}{*}{ AOR $95 \% \mathrm{Cl}$} & \multirow[t]{2}{*}{$P$-value } \\
\hline & Yes & No & & & \\
\hline \multicolumn{6}{|l|}{ Sex of the child } \\
\hline Male & 114 & 318 & 1.00 & 1.00 & \\
\hline Female & 205 & 174 & $0.31(0.12,0.83)$ & $0.40(0.21,0.86)^{a}$ & $<0.001$ \\
\hline \multicolumn{6}{|l|}{ Age of mother } \\
\hline 35 years and less & 274 & 362 & 1.00 & 1.00 & \\
\hline Older than 35 years & 45 & 130 & $2.18(1.42,4.10)$ & $1.75(1.15,3.86)^{\mathrm{a}}$ & 0.03 \\
\hline \multicolumn{6}{|l|}{ Colostrum feeding } \\
\hline Yes & 213 & 303 & 1.00 & 1.00 & \\
\hline No & 106 & 189 & $1.25(1.04,3.18)$ & $1.26(1.09,2.87)^{\mathrm{a}}$ & 0.02 \\
\hline \multicolumn{6}{|c|}{ Exclusive BF in the first six months } \\
\hline Yes & 248 & 350 & 1.00 & 1.00 & \\
\hline No & 71 & 142 & $1.42(1.12,5.25)$ & $1.34(1.23,3.92)$ & 0.18 \\
\hline \multicolumn{6}{|l|}{ Cessation of breast feeding } \\
\hline Before two years & 258 & 200 & 1.00 & 1.00 & \\
\hline Two years and beyond & 234 & 119 & $0.65(0.10,0.92)$ & $0.48(0.12,0.88)^{a}$ & $<0.001$ \\
\hline \multicolumn{6}{|c|}{ Frequency of complementary feeding } \\
\hline At least 3 times per day & 198 & 164 & 1.00 & 1.00 & \\
\hline Less than 3 times per day & 121 & 328 & $3.27(1.23,6.41)$ & $3.01(1.48,5.58)^{\mathrm{a}}$ & 0.01 \\
\hline \multicolumn{6}{|c|}{ Diarrheal morbidity in the past 12 months } \\
\hline Yes & 274 & 441 & 1.00 & 1.00 & \\
\hline No & 45 & 51 & $0.70(0.10,0.97)$ & $0.42(0.15,0.94)^{a}$ & $<0.001$ \\
\hline
\end{tabular}


Table 5 Factors associated with underweight among children aged between six to fifty nine months, rural kebeles of Hawassa town, 2012, $(n=811)$

\begin{tabular}{|c|c|c|c|c|c|}
\hline \multirow[t]{2}{*}{ Explanatory Variables } & \multicolumn{2}{|c|}{ Underweight } & \multirow[t]{2}{*}{ COR 95\% Cl } & \multirow[t]{2}{*}{ AOR 95\% Cl } & \multirow[t]{2}{*}{$P$-value } \\
\hline & Yes & No & & & \\
\hline \multicolumn{6}{|l|}{ Sex of the child } \\
\hline Male & 69 & 363 & 1.00 & 1.00 & \\
\hline Female & 59 & 320 & $0.87(0.42,0.93)$ & $0.84(0.21,2.86)$ & 0.08 \\
\hline \multicolumn{6}{|l|}{ Maternal formal education } \\
\hline No formal education & 49 & 318 & 1.00 & 1.00 & \\
\hline Have formal education & 79 & 365 & $0.71(0.28,0.96)$ & $0.68(0.30,0.93)^{a}$ & $<0.001$ \\
\hline \multicolumn{6}{|l|}{ Family size } \\
\hline Less than four & 82 & 189 & 1.00 & 1.00 & \\
\hline Four and above & 46 & 494 & $4.65(2.89,11.30)$ & $4.16(2.47,9.68)^{a}$ & 0.02 \\
\hline \multicolumn{6}{|c|}{ Exclusive BF in the first six months } \\
\hline Yes & 57 & 541 & 1.00 & 1.00 & \\
\hline No & 71 & 142 & $0.21(0.02,0.75)$ & $0.38(0.13,2.72)^{\mathrm{a}}$ & 0.03 \\
\hline \multicolumn{6}{|l|}{ Cessation of breast feeding } \\
\hline Before two years & 66 & 392 & 1.00 & 1.00 & \\
\hline Two years and beyond & 62 & 291 & $0.79(0.28,0.92)$ & $0.71(0.32,0.88)^{\mathrm{a}}$ & $<0.001$ \\
\hline \multicolumn{6}{|c|}{ Frequency of complementary feeding } \\
\hline At least 3 times per day & 87 & 275 & 1.00 & 1.00 & \\
\hline Less than 3 times per day & 41 & 408 & $3.14(1.23,5.41)$ & $2.87(1.62,5.38)^{\mathrm{a}}$ & 0.01 \\
\hline \multicolumn{6}{|l|}{ Practiced bottle feeding } \\
\hline Yes & 28 & 229 & 1.00 & 1.00 & \\
\hline No & 100 & 454 & $0.55(0.09,0.82)$ & $0.47(0.14,1.36)$ & 0.07 \\
\hline \multicolumn{6}{|c|}{ Diarrheal morbidity in the past 12 months } \\
\hline Yes & 97 & 618 & 1.00 & 1.00 & \\
\hline No & 31 & 65 & $0.32(0.10,0.84)$ & $0.28(0.15,0.74)^{\mathrm{a}}$ & $<0.001$ \\
\hline
\end{tabular}

$29 \%$ and $10 \%$ of the children were stunted underweight and wasted respectively [6]. This study also indicated lower prevalence of undernutrition among children than a number of studies conducted in different parts of the country $[2,8,12-15]$. This lower prevalence of undernutrition could be attributed to that the study area is green and different fruits and vegetables that are rich with different nutrients are harvested in the area. However, prevalence of undernutrition in our study was higher than a comparative cross sectional study conducted in Nepal (except for wasting) in which prevalence of underweight, stunting and wasting was reported as $27 \%, 37 \%$ and $11 \%$ respectively [16]. Our research finding also showed higher prevalence of undernutrition than other studies conducted in different parts of Ethiopia [10, 17-19]. As observed from these literatures, there were improvements of undernutrition over time. This could be attributed to the efforts of the health sector to enhance good nutritional practices through health education and provision of micronutrients to the most vulnerable group. In addition, the health extension programme has included nutrition as one part of its packages.

The finding of this study showed that the prevalence of undernutrition increases with age. Prevalence of all forms of undernutrition in the younger age group was lower as compared with older children peaking at the age groups of 36-47 months. Our finding is consistent with a study conducted in northern part of Ethiopia in which undernutrition was found to be peak (66.7\%) at the age of 12-23 months [20]. It is also inconsistence with the study conducted at Butajira where undernutrition was reported to be peaking at 12 months $(21.2 \%$ underweight, $48.1 \%$ stunted and $8.4 \%$ wasted) than 6 months $(21.7 \%$ underweight, $26.7 \%$ stunted and $16.7 \%$ wasted) [21]. It is also consistent with the results of researches in other African countries Congo [22] and South Africa where underweight was associated with age less than 12 months [23]. This might be due to the protective 
Table 6 Factors associated with wasting among children aged between six to fifty nine months, rural kebeles of Hawassa town, 2012, $(n=811)$

\begin{tabular}{|c|c|c|c|c|c|}
\hline \multirow[t]{2}{*}{ Explanatory Variables } & \multicolumn{2}{|c|}{ Wasting } & \multirow[t]{2}{*}{ COR 95\% Cl } & \multirow[t]{2}{*}{ AOR 95\% Cl } & \multirow[t]{2}{*}{$P$-value } \\
\hline & Yes & No & & & \\
\hline \multicolumn{6}{|l|}{ Preceding birth interval } \\
\hline 24 months and above & 43 & 623 & 1.00 & 1.00 & \\
\hline Less than 24 months & 8 & 137 & $1.18(1.08,2.56)$ & $1.21(1.11,2.34)^{\mathrm{a}}$ & 0.03 \\
\hline \multicolumn{6}{|c|}{ Number of under-five children in the $\mathrm{HHs}$} \\
\hline One child & 38 & 490 & 1.00 & 1.00 & \\
\hline More than one children & 13 & 270 & $1.61(1.21,6.85)$ & $1.48(1.16,4.82)^{a}$ & 0.006 \\
\hline \multicolumn{6}{|l|}{ Colostrum feeding } \\
\hline Yes & 35 & 481 & 1.00 & 1.00 & \\
\hline No & 16 & 279 & $1.26(1.14,3.28)$ & $1.22(1.10,2.97)^{\mathrm{a}}$ & 0.04 \\
\hline \multicolumn{6}{|c|}{ Frequency of complementary feeding } \\
\hline At least 3 times per day & 29 & 333 & 1.00 & 1.00 & \\
\hline Less than 3 times per day & 22 & 427 & $1.69(1.19,5.11)$ & $1.58(1.23,4.48)^{\mathrm{a}}$ & 0.01 \\
\hline \multicolumn{6}{|l|}{ Cessation of breast feeding } \\
\hline Before two years & 22 & 436 & 1.00 & 1.00 & \\
\hline Two years and beyond & 29 & 324 & $0.56(0.10,0.92)$ & $0.48(0.12,0.88)^{a}$ & $<0.001$ \\
\hline \multicolumn{6}{|l|}{ Practiced bottle feeding } \\
\hline Yes & 11 & 246 & 1.00 & 1.00 & \\
\hline No & 40 & 514 & $0.57(0.19,0.92)$ & $0.52(0.14,0.86)^{a}$ & $<0.001$ \\
\hline
\end{tabular}

${ }^{a}$ Statistically significant association

effect of breast-feeding against malnutrition, since breast feeding is universal in Ethiopia as almost all (90\%) children are breast-fed and most continue to breast-feed during their first year of life [6].

Parental socio demographic variables are found to be independently associated with children's undernutrition. Maternal age was significantly associated with children's undernutrition as children born to mothers aged 35 years and above were more likely to be stunted as compared to those who born to mothers aged less than 35 years. This finding is similar to the finding of study conducted in the Ethiopia [13]. Children of mothers with no formal education were more likely to be underweight when compared with children of educated mothers. This is consistent with study conducted in Ethiopia, [2, 24] Democratic Republic of Congo [22] and Bangladesh and Pakistan [23, 25] which showed parental education status was positively associated with child undernutrition. It is obvious that educated mothers are more autonomous to make decisions on resource allocation to nourish their children. It may also be attributed to better childcare practices adopted by educated mothers than those by uneducated mothers.

Birth interval was independently associated with wasting as children born within 24 months of the preceding siblings were more likely to be wasted than those who born after 24 months. This study also identified that children born to a household with more than four family size were more likely to be underweight when compared to children from a household with less than four family size. This finding is in line with the study conducted in Vietnam and Bangladesh [22, 25]. This could be because families with more children experience more economic strain for food consumption and hence they are more likely to suffer from poor nutritional status.

The children's individual factors were also found to be independently associated with undernutrition among children. Sex of the child and diarrheal morbidity were found to be significantly associated with stunting. Presence of diarrheal morbidity in the last one year prior to data collection period was significantly associated with stunting and underweight. The results of this study are in agreement with the results of studies conducted in different developing countries [26-29]. This is because diarrhea may result in lower appetite and poor digestion and mal-absorption. Compared to boys, the likelihood of stunting was lower among girls. Similarly, many studies in Ethiopia and elsewhere have reported that under-five male children are more likely to become stunted than their female counterparts [8, 29-32]. This could be because of boys are more influenced by environmental factors including diet than girls [30]. Birth interval and bottle feeding practice are independently associated with wasting. Children who were born in less than 24 months 
of the preceding birth were more likely to be wasted as compared with children born beyond 24 months. Children who practiced bottle feeding were more likely to be wasted than those who didn't practice bottle feeding. The results of this study are in agreement with results of studies conducted in Ethiopia [3, 8]. This could be attributed to that bottle feeding is one of the factors that can result in diarrhea which end in undernourishment.

Sub-optimal early child feeding practices were also found to be statistically associated with nutritional status of children. Children breastfed for less than 2 years were more likely to be undernourished; stunted, underweight and wasted. The odds of stunting were lower among children who started complementary feeding at 6 months or later when compared with children started complementary feeding before the age of 6 months. Children who fed complementary feeding for less than three times per day were more likely to be stunted, underweight and wasted than their counterparts. This finding was consistent with the finding from similar study in which frequency of daily complementary feeding led to child stunting [2, 24, 30,33]. This might be due to inadequate intake of nutrients from complementary foods that increases the risk of undernutrition. The finding could also be attributed that complementary feeding could be contaminated that may lead to diarrheal disease which inturn causes undernutrition. This study showed that children who didn't feed on colostrum were more likely to be stunted and wasted than those who received it. Similar findings are reported in India [34] This is probably because colostrum are full of nutrients and antibodies which provide protective effect to the children and prevent them from infections that may cause malnutrition.

This study was suffered from different limitations. An important limitation of this study is the cross sectional nature of the design that poses difficulty to examine causal relationship among variables. Secondly, much of the data were obtained via self report which can lead to a potential recall bias to the events happened in the past about child's history of illness and patterns of breastfeeding. Finally, information on some important confounders such as parasitic infection, HIV status and maternal nutritional status during pregnancy were not collected which can affected nutritional status of the children.

\section{Conclusion}

This study revealed significantly high prevalence of undernutrition (stunting, underweight and wasting) among children aged six to fifty nine months in the study area. Undernutrition was found to be significantly associated with age and educational status of the mothers, family size, birth interval, early child's feeding, bottle feeding practice and diarrheal morbidity. Much more effort should be undertaken at all levels to improve information, education and communication on awareness creation regarding young child feeding practice as per the national infant and young child feeding practice guideline. Further research should be conducted to investigate specific nutrient deficiency in body serum by using laboratory methods. Health care providers need to deliver quality nutrition interventions and mothers should be advised about nutrition during pregnancy in order to reduce the consequence undernutrition.

\begin{abstract}
Abbreviations
ANC: antenatal care; AOR: adjusted odds ration; Cl: confidence interval; COR: crude odds ration; EDHS: Ethiopian demographic and health survey; ENA: emergency nutrition assessment; HAZ: height for age Z-score; HEP: health extension program; HIV: human immunodeficiency virus; SD: standard deviation; SNNPR: Southern Nation and Nationalities and People Region; SPSS: statistical package for social science; UNICEF: United Nations international children's emergency fund; WAZ: weight for Age Zscore; WHO: World health organization; WHZ: height for weight Z-score
\end{abstract}

\begin{abstract}
Acknowledgment
We would like to express our deepest gratitude to Federal Ministry of Health and World Bank Nutrition Project Ethiopia for support this research work. We would also like to express our appreciation to all study participants and the community in which this research was conducted for their cooperation during data collection period. Last but not least, we would like to extend our gratitude to all individuals who reviewed and provide us technical support to the successful completion of this research work.
\end{abstract}

Funding

The authors have got no funding from any organization or individuals.

\section{Availability of data and materials}

The datasets used and during the current study is available from the corresponding author on reasonable request.

\section{Authors' contributions}

HD has made substantial contributions from inception of the research idea to proposal development, data collection, analysis and interpretation of data and preparation of the manuscript. AG has participated in conception of research idea, proposal development, data collection, data analysis and preparation of the manuscript for publication. AG has participated in proposal development, data collection, data analysis and manuscript preparation. SM has also contributed for proposal development, data collection, data analysis and preparation of the manuscript. All the authors read and approved the final version of the manuscript.

\section{Authors' information}

$\mathrm{HD}$ has master of public health and currently working in Federal Ministry of Health, Ethiopia, Nutrition program directorate as program coordinator. AG has Master of Public Health and currently working in College of Health and Medical Science, Department Of Public Health, Haramaya University as a lecturer. AG has Doctor of philosophy in public health and currently working in Institute of Public health, College of Health and Medical Science, University of Gondar as assistant professor. SM has master of public health and currently working in Institute of Public health, College of Health and Medical Science, University of Gondar as assistant professor.

\section{Competing interests}

The authors confirm that there were no competing interests.

\section{Consent for publication}

Consent for publication was obtained from the study participants and their partners during data collection. 


\section{Ethics approval and consent to participate}

Ethical clearance was obtained from Ethical Review Board of the Institute of Public Health, University of Gondar. Official letter of cooperation was written to Hawassa city administration health office by SNNPRs regional health bureau ethical review committee. Subsequently, permission from Tulla Sub city health office was obtained and each administration of the kebele was informed through letter from the sub city. Written and signed informed consent was obtained from each respondent after the purpose of the study and assurance of confidentiality was explained. It was explained to the participants that participation was voluntary. Participants with diarrhea, respiratory tract infections and undernutrition were referred to nearby health facilities for management.

\section{Publisher's Note}

Springer Nature remains neutral with regard to jurisdictional claims in published maps and institutional affiliations.

\section{Author details}

${ }^{1}$ MCHN Directorate, Federal Ministry of Health, Addis Ababa, Ethiopia. ${ }^{2}$ School of Public Health, College of Health and Medical Science, Haramaya University, Harar, Ethiopia. Institute of Public Health, Gondar College of Health and Medical Science, University of Gonder, Gonder, Ethiopia.

Received: 15 November 2016 Accepted: 26 April 2017

Published online: 10 July 2017

\section{References}

1. Black RE, Allen LH, Bhutta ZA, Caulfield LE, de Onis M, Ezzati M, et al. Maternal and child undernutrition: global and regional exposures and health consequences. Lancet. 2008;371(9608):243-60.

2. Mandefro A, Mekitie W, Mohammed, and Lamessa D. Prevalence of undernutrition and associated factors among children aged between six to fifty nine months in Bule Hora district, South Ethiopia. BMC Public Health. 2015;15:41. DOI 10.1186/s12889-015-1370-9

3. Singer PA, Ansett $S$, Sagoe-Moses I. What could infant and young child nutrition learn from sweatshops? BMC Publ Health. 2011;11:276.

4. Oystein K, Ivy K. Children's Stunting in Sub-Saharan Africa: Is there an Externality Effect of High Fertility? Demogr Res. 2011;25(18):565-94.

5. Central Statistical Agency and ICF International. Ethiopia Demographic and Health Survey 2011. Addis Ababa: CSA and ICF International; 2012.

6. Kar BR, Rao SL, Chandramouli BA. Cognitive development in children with chronic protein energy malnutrition. Behav Brain Funct. 2008;4:31.

7. Addis Continental Institute of Public Health. Community-Based Sub-Component of Ethiopian National Nutrition Program Baseline Survey Report 2009. aciph 1stround_cbn_baseline.pdf. Available online from December 04, 2009.

8. Teshome B, Kogi-Makau W, Getahun Z, Taye G. Magnitude and determinants of stunting in children underfive years of age in food surplus region of Ethiopia: the case of west gojam zone. Ethiop J Health Dev. 2009: 23(2):99-106.

9. Hien NN, Kam S. Nutritional status and the characteristics related to malnutrition in children under five years of age in Nghean, Vietnam. J Prev Med Public Health. 2008;41:232-40

10. Solomon D, Amare W. Magnitude and Factors Associated with Malnutrition in Children 6-59 Months of Age in Pastoral Community of Dollo Ado District, Somali Region, Ethiopia. Sci J Public Health. 2013;1(4):175-83. doi:10. 11648/j.sjph.20130104.12

11. Onis MD, Blossner M, Borghi E. Prevalence and Trends of Stunting among pre-school children, 1990-2020. Public Health Nutr. 2011;15:142-8.

12. Mulugeta M. Systematic Reviews of Prevalence and Associated Factors of Under Five Malnutrition in Ethiopia: Finding the Evidence. Int J Nutr Food Sci. 2015;4(4):459-64. doi:10.11648/j.jijnfs.20150404.17.

13. Herrador Z, Sordo L, Gadisa E, Moreno J, Nieto J, et al. Cross-Sectional Study of Malnutrition and Associated Factors among School Aged Children in Rural and Urban Settings of Fogera and Libo Kemkem Districts, Ethiopia. PLOS ONE. 2014;9(9), e105880. doi:10.1371/journal.pone.0105880.

14. Mengistu K, Alemu K, Destaw B. Prevalence of Malnutrition and Associated Factors Among Children Aged 6-59 Months at Hidabu Abote District, North Shewa, Oromia Regional State. J Nutr Disorders Ther. 2013;T1:001. doi:10. 4172/2161-0509.T1-001.

15. Yalew BM. Prevalence of Malnutrition and Associated Factors among Children Age 6-59 Months at Lalibela Town Administration, North
WolloZone, Anrs, Northern Ethiopia. J Nutr Disorders Ther. 2014;4:132. doi: 10.4172/2161-0509.1000132.

16. Sapkota V, Gurung C. Prevalence and Predictors of Underweight, Stunting and Wasting in Under-Five Children. J Nepal Health Res Counc. 2009;7(15): 120-6.

17. Girmay M, Charlotte H, Michael D, Atalay A, Fikru T, Bogale W, Mark T, Martin P. Prevalence and predictors of undernutrition among infants aged six and twelve months in Butajira, Ethiopia: The P-MaMiE Birth Cohort. BMC Public Health. 2010:10:27.

18. Firehiwot M, Yemane B and Alemayehu W. Prevalence and associated factors of stunting among primary school children in eastern Ethiopia. Dove Press, Nutrition and Dietary Supplements 2015:7 61-68. Accessed at: http:// dx.doi.org/10.2147/NDS.S80803

19. Tilahun A, Abraham D, Berhanu E. Prevalence and factors associated with undernutrition and anaemia among school children in Durbete Town, northwest Ethiopia. BMC Arch Public Health. 2015;73:34. doi:10.1186/s13690015-0084-x.

20. Asres G, Eidelman A. Nutritional Assessment of Ethiopian Beta-Israel Children. Breastfeed Med. 2011;6(4):171.

21. Medhin $\mathrm{G}$, et al. Prevalence and predictors of undernutrition among infants aged six and twelve months in Butajira, Ethiopia: The P-MaMiE Birth Cohort. BMC Public Health. 2010:10:27.

22. Lesiapeto M, Smuts C, Hanekom S. Risk Factors of Poor Anthropometric Status in Children Under Five Years of Age. S Afr J Clin Nutr. 2010;23(4):202-7.

23. Ngianga BK, Tumwaka PM, Jacques BE, Kikhela PD, Francesco PC. Malnutrition among children under the age of five in the Democratic Republic of Congo (DRC): does geographic location matter? BMC Public Health. 2011;11:261-76.

24. Gudina E, Yemane B, Alemayehu W. Predictors of acute undernutrition among children aged 6 to 36 months in east rural Ethiopia: a community based nested case - control study. BMC Pediatr. 2014;14:91.

25. Islam MM, Alam M, Tariquzaman M, Kabir MA, Pervin R, Begum M, et al. Predictors of the number of under-five malnourished children in Bangladesh: application of the generalized poisson regression model. BMC Public Health. 2013:13(11):1-8.

26. Wamani H, Astrom A, Peterson S. Prevalence and determinants of stunting and overweight in 3-year old black. S Afr Child J Public Health Nutr. 2007;8: 501-8.

27. Amita P. Factors associated with nutritional status of the under five children Asian J Med Sci. 2010;10:6-8.

28. Nguyen N. Nutritional Status and Determinants of Malnutrition in Children Under Three Years of Age. Pak J Nutr. 2009:8(7):958-64

29. Deribew A, Alemseged F, Tessema F, Sena L, Birhanu Z, Sudhakar M, et al. Biadgilign: malaria and under-nutrition: a community based study among under-five children at risk of malaria, south-west Ethiopia. PLoS One. 2010; 5(5), e10775.

30. Hien N, Hoa N. Nutritional status and determinants of malnutrition in children under three years of Age in Nghean. Vietnam Pak J Nutr. 2009:8(7): 958-64.

31. Olack B, Burke $H$, Cosmas L, Bamrah $S$, Dooling $K$, Feikin DR, et al. Nutritional status of under-five children living in an informal urban settlement in Nairobi, Kenya. J Health Popul Nutr. 2011;29(4):357-63.

32. Demissie S, Worku A. Magnitude and Factors Associated with Malnutrition in Children 6-59 Months of Age in Pastoral Community of Dollo Ado District, Somali Region, Ethiopia. Sci J Public Health. 2013;1 (4):175-83.

33. Amsalu S, Tigabu Z. Risk factors for severe acute malnutrition in children underthe age of five: a case - control study. Ethiop J Health Dev. 2008;22(1): $21-5$

34. Kumar D, Goel N, Mittal P, Misra P. Influence of infant-feeding practices on nutritional status of under-five children. Indian J Pediatr. 2006;73(5):417-21. 